\title{
Ecological Studies on Two Amphiprion Species in Maldivian Coral Reefs
}

\author{
R.A. Patzner* \\ Department of Organismic Biology, University of Salzburg, Hellbrunnerstr. 34, 5020 Salzburg, Austria
}

\begin{abstract}
Amphiprion clarkii and A. nigripes were found in coral reefs of three different atolls in the Maldives. A. clarkii was associated with five species of host anemones, but A. nigripes was only found in Heteractis magnifica. In few cases, both anemonefishes have utilized the same individual of $\mathrm{H}$. magnifica. There was no significant correlation between the size of the anemones and the number of the inside living Amphiprion.
\end{abstract}

\section{INTRODUCTION}

All Amphiprion species are strongly depending on habitat structure and availability of certain host sea anemone species. Therefore, abundance and size of sea anemones are controlling the size of anemonefish populations (Richardson EBF 1999 and references herein) [1]. The Maldivian fauna has a relatively poor number of Amphiprion species. Just $A$. clarkii (Bennett, 1830), A. nigripes Regan, 1908 and A. sebae, Bleeker 1853 exist (Fautin WAM 1992) [2]. The latter is the only associated with Stichodactyla haddoni (SavilleKent, 1893) which lives on sand and therefore was not observed in the present study. In Papua New Guinea the highest reported anemonefish diversity with 9 species is found (Elliott MB 2001) [3]. A. clarkii is the most widely distributed anemonefish ranging from the western Pacific to the Persian Gulf and from Japan to Australia whereas A. nigripes is endemic to the Maldives and Sri Lanka in the central Indian Ocean. A. clarkii is the highest host specific Amphiprion species which can be associated with ten host anemone species. Whereas A. nigripes usually is associated with only one anemone (Fautin WAM 1992) [2].

In August 1998, mass bleaching of corals occurred in many coral reefs around the world (Glynn BMS 2001) [4]. This bleaching caused not only the loss of many stone and soft corals, but also many anemones disappeared (Loch Das Aquarium 2003) [5], (Hattori IR 2005) [6]. Additionally, investigations on Amphiprion and their host anemones in the Maldives are rare. However, there exist some studies by Loch and Loch (Das Aquarium 1999, Das Aquarium 2003) [5] [7], precise data are still lacking. Therefore, the aim of this study was to get knowledge of the current situation of anemones and their hosts 10 years after the coral reefs had been destroyed by the bleaching process.

\section{MATERIALS AND METHODOLOGY}

Throughout the 'Expedition of Maldives 2007' in 24 different transects of North Male Atoll, Rasdhoo Atoll, Ari Atoll and South Male Atoll 173 host anemones were studied in March 2007 (Fig. 1). Observations were made on coral reefs using SCUBA, between a water depth of 1 and $15 \mathrm{~m}$ and in a

*Address correspondence to this author at the Department of Organismic Biology, University of Salzburg, Hellbrunnerstr. 34, 5020 Salzburg, Austria; Tel +43 6628044 5619; Fax +43 66280445698 ;

E-mail; robert.patzner@sbg.ac.at length of $70 \mathrm{~m}$ for each transect. The following parameters were considered: species of Amphiprion, species of anemone, size of the anemone, water depth (in strata of $1-4.9 \mathrm{~m}$, $5-9.9 \mathrm{~m}$, and $10-15 \mathrm{~m}$ ), number of adult Amphiprion, number of juvenile Amphiprion (3 size classes), and number of host anemone per $1,000 \mathrm{~m}^{2}$ (with reference to Chadwick JMBA 2005) [8]. The size of an anemone was determined by measuring the lengths between the tentacle tips on both the long and short axes. The size, to the nearest $5 \mathrm{~cm}$, was calculated by the formula of: long length $\mathrm{x}$ short length $\mathrm{x} \pi / 4$ (Hirose Galaxea 1985) [9].

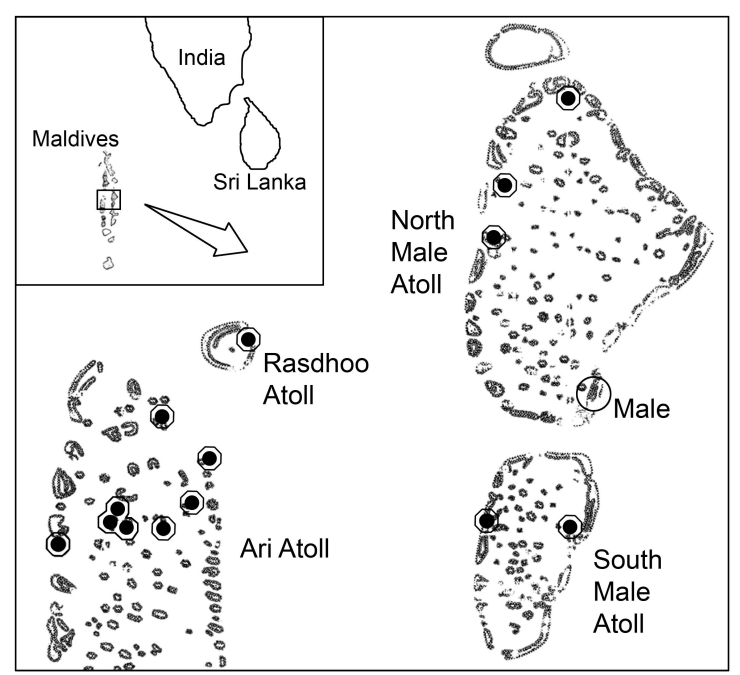

Fig. (1). Map showing the position of study sites at Maldives. Circle: start and end point of expedition; filled circles: investigated coral reefs with transects.

\section{RESULTS}

\section{Host Anemones}

In the studied area of the Maldivian coral reefs, five species of host anemones were found: Cryptodendrum adhesivum Klunzinger, 1877, Entacmaea quadricolor (Rüppel and Leuchart, 1828), Heteractis aurora (Quoy and Gaimard, 1833), Heteractis magnifica (Quoy and Gaimard, 1833), and Stichodactyla mertensii (Brandt, 1835). Each of them was at least harboured by one individual of Amphiprion. No 'vacant' anemones could be observed. The density of anemones within one transect varied between 0.5 and 11.4 per 1,000 $\mathrm{m}^{2}$, with a mean of 3.1 . 
A special case was observed at the island of Kandholudhoo (Ari-Atoll, $\mathrm{N}^{\circ} 00,221^{\prime} \mathrm{E} 72^{\circ} 52,153^{\prime}$ ), A dense field of Heteractis magnifica was found all associated with Amphiprion nigripes. A number of 58 individuals of anemones were counted at a water depth of 3.5 to $11.5 \mathrm{~m}$ and in an area of 10.5 to $5.5 \mathrm{~m}$. This represents a density of about one anemone per square meter.

There was no significant correlation between the size of the anemones and the water depth (Pearson's correlation analysis: H. aurora $\mathrm{r}=0.206, H$. magnifica $\mathrm{r}=0.058$, and $S$. mertensii $\mathrm{r}=0.182$ ). The number of $C$. adhesivum and $E$. quadricolor was too low for the statistical analysis.

\section{Amphiprion clarkii (Bennett, 1830)}

In $80 \%$ of the observations, two adult animals were present in one anemone. In $17 \%$, one adult and in $3 \%$, no adult could be found. The number of juveniles in one anemone varied between zero and nine, with a mean of 2.2. Amphiprion clarkii could be observed in 5 different species of host anemones. Most of the fish were in an association with Heteractis aurora (39\%) and Stichodactyla mertensii (35 $\%)$. The other hosts were Entacmaea quadricolor (17\%), Heteractis magnifica (6 \%) and Cryptodendrum adhesivum (3\%) (Fig. 2). There was a correlation between the size of the anemone and the number of $A$. clarkii living in, however, it was not highly significant (Pearson's correlation analysis: $r$ $=0.313)$.

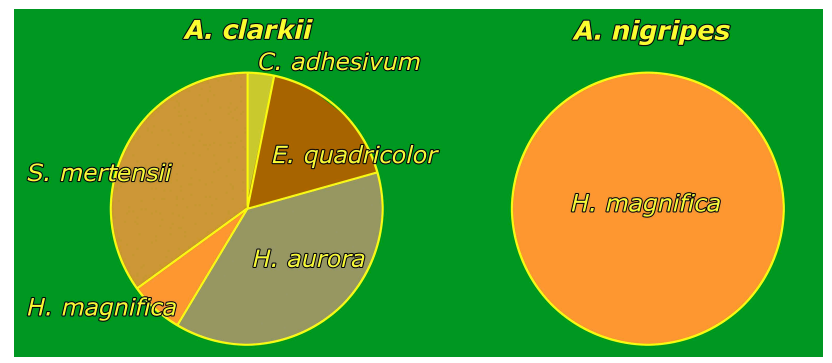

Fig. (2). Percentage of host anemones harbouring Amphiprion clarkii and A. nigripes, respectively.

\section{Amphiprion nigripes Regan, 1908}

In $99 \%$ of the observations, two adult $A$. nigripes were seen in one anemone. In one small $H$. magnifica $\left(80 \mathrm{~cm}^{2}\right)$ only one juvenile was present. The number of juveniles in one anemone varied from zero to seven, with a mean of 1.3. Amphiprion nigripes was only found to be associated with the anemone Heteractis magnifica (110 observations) (Fig. 2). There was no significant correlation between the size of the anemone and the number of fish living in (Pearson's correlation analysis: $r=0.176$ ).

The depth distribution of anemones, which utilized by $A$. nigripes, showed also no clear differences at the different depth strata. At $1-4.9 \mathrm{~m}, 5-9.9 \mathrm{~m}$, and $10-15 \mathrm{~m} ; 36 \%, 19$ $\%$, and $45 \%$ of the anemones were observed, respectively.

\section{Amphiprion clarkii and $A$. nigripes}

In three cases (1.7\% of total observations), both species of Amphiprion were utilizing the same host sea anemone. The anemones were always Heteractis magnifica (Fig. 3). In case number one, 1 adult $A$. clarkii was observed with 2 adult, 1 juvenile size 3 , and 2 juveniles size 2 of $A$. nigripes in an anemone of $1,250 \mathrm{~cm}^{2}$ at $15 \mathrm{~m}$ water depth. In case number two, 1 adult $A$. clarkii was observed with 2 adult, 1 juvenile size 3 , and 1 juvenile size 2 of A. nigripes in an anemone of $940 \mathrm{~cm}^{2}$ at a depth of $14.8 \mathrm{~m}$. In case number three, 1 adult $A$. clarkii was found with 1 juvenile size 3 of A. nigripes in an anemone of $310 \mathrm{~cm}^{2}$ at a depth of $14.5 \mathrm{~m}$.

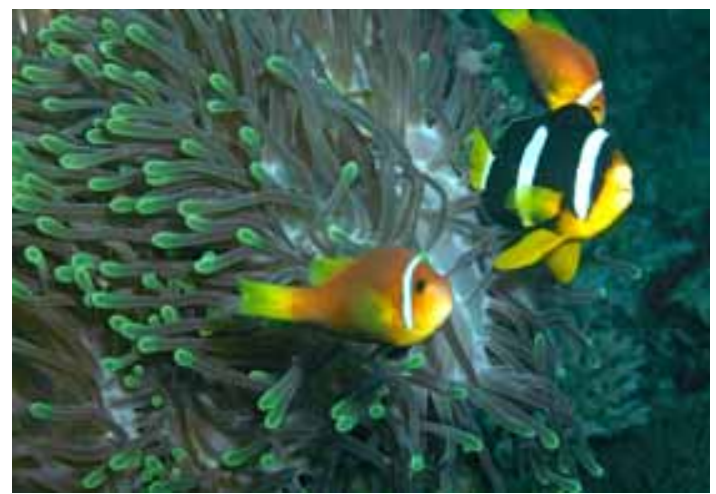

Fig. (3). Amphiprion clarkii and A. nigripes utilizing the same host anemone (Heteractis magnifica).

\section{DISCUSSION}

In the Maldives, a third species of Amphiprion, A. sebae with the host anemone Stichodactyla haddoni, is indicated (Fautin WAM 1992) [2]. However, as only coral reefs were investigated in the current study, this anemone was not detected because it lives only on sandy bottoms (Fautin WAM 1992) [2]. Also the elsewhere widely distributed anemone Heteractis crispa (Ehrenberg, 1834) was not found during the investigation. The latter species was severely affected by the coral bleaching of 1997/98 and has disappeared from many locations (Loch Das Aquarium 2003) [5]. No data are available for the density of host anemones in the Maldives before and after the coral bleaching. Loch and Loch (Das Aquarium 2003) [5] reported that most of $H$. magnifica and other anemone species had died because of the bleaching (without giving any concrete data). Worldwide the density of host anemones in coral reefs is widely different and varies between two anemones in Okinawa, Japan to 500 per 1,000 $\mathrm{m}^{2}$ in Solidary Island, Australia (Hattori JJI 1991) [10], (Richardson EBF 1999) [1]. In anemone colonies a high density can be reached. Fricke (ZT 1979) [11] found at the Aldabra Atoll a field of 198 single host anemones, covering an area 6 by $3.5 \mathrm{~m}$, which means 9,428 anemones per 1,000 $\mathrm{m}^{2}$.

The distribution density of both species of Amphiprion in the present study showed that they do not have any depth preference, at least within the investigated depth range (1 to 15 m). Richardson (EBF 1999) [1] reported from Australia that the distribution of Amphiprion latezonatus showed a significant correlation with the depth, but Amphiprion akindynos in the same area did not show.

In Heteractis crispa, Hattori (JE 2006) [12] found that the sizes of anemones were positively correlated with their water depth in Japan. However, in the present investigation, the size of the three most common host anemones showed a very weak correlation with the water depth.

A utilization of one host anemone by two species of Amphiprion was previously reported by Hattori (EBF 1995, JAE 
2002) [13] [14] from southern Japan and by Loch and Loch (Das Aquarium 1999, Das Aquarium 2003) [5] [7] from the Maldives. In Japan, $A$. clarkii and $A$. perideraion were found together in Heteractis crispa. This combination was quite common and found in $32.5 \%$ of the observations. In the Maldives, A. clarkii and A. nigripes were found together in Heteractis magnifica and also in Stichodactyla mertensii. The latter combination is the first report, where A. nigripes is associated with an anemone other that $H$. magnifica. Loch and Loch (Das Aquarium 2003) [7] showed photographs and inform about $S$. mertensii which is harbouring an adult pair of $A$. nigripes and three juveniles of $A$. clarkii. This observation was made in 1997 when the coral bleaching had already started; that means that there was a scarcity of anemones.

\section{ACKNOWLEDGEMENTS}

I thank Mattias Seidl and the 'Fundus Gruppe' (Germany) for the financial support and Karen and Wolfgang Loch for the organization of the expedition.

\section{REFERENCES}

[1] Richardson DL. Correlates of environmental variables with patterns in the distribution and abundance of two anemonefishes (Pomacentridae: Amphiprion) on an eastern Australian sub-tropical reef system. Env Biol Fish 1999; 55: 255-263.

[2] Fautin DG, Allen GR. Anemonefishes and their host sea anemones. Western Australian Museum: Perth 1992.

[3] Elliott JK, Mariscal RN. Coexistence of nine anemonefish species: differential host and habitat utilization, size and recruitment. Mar Biol 2001; 138: 23-36.
[4] Glynn PW, Mate JL, Baker AC, Calderon MO. Coral bleaching and mortality in Panama and Ecuador during the 1977-1998 El Ninosouthern oscillation event: spatial/temporal patterns and comparisons with the 1982-1983 event. Bull Mar Sci 2001; 69: 79-109.

[5] Loch K, Loch W. Kombinierte Symbiose von Amphiprion clarkii und A. nigripes mit Stichodactyla mertensii. Das Aquarium 2003; 403: 39-41.

[6] Hattori A. High mobility of the protandrous anemonefish Amphiprion frenatus: nonrandom pair formation in limited shelter space. Ichthyol Res 2005; 52: 57-63.

[7] Loch K, Loch W. Symbioseanemonen - Beobachtungen in maledivischen Korallenriffen. Das Aquarium 1999; 360: 35-42.

[8] Chadwick NE, Arvedlund M. Abundance of giant sea anemones and patterns of association with anemonefish in the northern Red Sea. J Mar Biol Ass UK 2005; 85: 1287-1292.

[9] Hirose Y. Habitat, distribution and abundance of coral reef seaanemones (Actiniidae and Stichodactylidae) in Sesoko Island, Okinawa, with notes on expansion and contraction behavior. Galaxea 1985; 4: 113-127.

[10] Hattori A. Social controlled growth and size-dependent sex change in the anemonefish Amphiprion frenatus in Okinawa, Japan. Japan J Ichthyol 1991; 38: 165-177.

[11] Fricke HW. Mating system, resource defence and sex change in the anemonefish Amphiprion akallopisos. Z Tierpsychologie 1979; 50: 313-326.

[12] Hattori A. Vertical and horizontal distribution patterns of the giant sea anemone Heteractis crispa with symbiotic anemonefish on a fringing coral reef. J Ethol 2006; 24: 51-57.

[13] Hattori A. Coexistence of two anemonefishes, Amphiprion clarkii and $A$. perideraion, which utilize the same host sea anemone. Env Biol Fish 1995; 42: 345-353.

[14] Hattori A. Small and large anemonefishes can coexist using the same patchy resources on a coral reef, before habitat destruction. J Anim Ecol 2002; 71: 824-831.

(C) R.A. Patzner; Licensee Bentham Open.

This is an open access article distributed under the terms of the Creative Commons Attribution License (http://creativecommons.org/license/by/2.5/), which permits unrestrictive use, distribution, and reproduction in any medium, provided the original work is properly cited. 